\title{
La violencia de hoy, las violencias de siempre
}

\author{
Elena Azaola
}

El presente trabajo desarrolla tres argumentos para explicar los actuales niveles de violencia que vivimos en México: I) la existencia de formas de violencia que han existido de tiempo atrás, sin vínculos con las actividades de grupos de delincuencia organizada, toleradas e incluso ignoradas, cuyos efectos, sumados a otros factores coyunturales, han contribuido al actual escalamiento de la violencia; 2 ) el debilitamiento y la descomposición de las instituciones de seguridad y procuración de justicia; 3 ) la insuficiencia de las políticas sociales y económicas para reducir las desigualdades y promover la inclusión de amplios sectores, así como una mayor y mejor articulación e integración de estas políticas en torno a fines comunes con las políticas de seguridad.

PALABRAS CLAVE: violencia, homicidios, delincuencia, políticas de seguridad, desigualdad, injusticia

\section{Violence of Today, Violence of All Time}

This article develops three arguments to explain the high levels of violence we experience today in Mexico: I) the prevalence of types of violence that have existed from long time ago, not related with organized crime groups, but tolerated and even ignored, in combination with other factors, they have fueled the current levels of violence; 2) the weakness and decomposition of the police and justice institutions, and 3) the inadequacy of social and economic policies to reduce inequality and to promote the inclusion of large sectors of population, and a larger and better integration of those policies with the security ones to define their common goals.

KEYWORDS: violence, homicide, delinquency, security policies, inequality, injustice

Elena Azaola: Centro de Investigaciones y Estudios Superiores en Antropología Social-Distrito Federal, México eazaola@ciesas.edu.mx 
Toda condena de la violencia es estéril si no va acompañada de la búsqueda de medios alternativos.

Para ser realmente una alternativa, la no violencia debería ser un procedimiento, una teoría y una práctica que cumpla con la misma función que la violencia organizada y que tenga la misma eficacia que los procedimientos que emplea la violencia para alcanzar una meta considerada valiosa: el poder, el bienestar, la paz, la libertad o la justicia.

Norberto Bobbio (2000: 197-198).

\section{INTRODUCCIÓN}

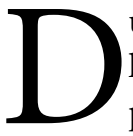
urante los últimos años diversos especialistas han ofrecido un conjunto de respuestas a la pregunta: ¿Cómo podemos explicar que la violencia hubiera escalado de manera tan abrupta entre 2007 y 2011 en nuestro país? Para Eduardo Guerrero, la política indiscriminada

de arrestos y abatimiento de capos contribuyó a incrementar la violencia hasta que ésta adquirió el carácter de epidemia, lo que la hizo más difícil de controlar. Guerrero también considera que los mercados ilegales oligopólicos tienden a registrar niveles más altos de violencia. Para Alejandro Hope fue el aumento en el precio de la cocaína, la disponibilidad de armas y la deportación masiva de exconvictos desde Estados Unidos lo que exacerbó la violencia. Por su parte, Fernando Escalante estima que el escalamiento de la violencia se encuentra asociado a los operativos federales, concretamente a la utilización del Ejército en labores de policía que no le corresponden. También se refiere al rompimiento de vínculos sociales comunitarios y a formas de control tradicional que dejaron de operar, así como al cierre o mayor control de las fronteras.

Ana Laura Magaloni atribuye esta intensificación de la violencia a que las políticas de seguridad han privilegiado el uso de la fuerza, por encima del de la ley. Señala que policías y militares cometen abusos por la falta de contrapesos provenientes de un sistema de justicia colapsado y al que se decidió deliberadamente no fortalecer. Joaquín Villalobos relaciona la multiplicación de la violencia con el mercado de drogas, la evolución de los grupos delincuenciales, la debilidad de las instituciones y el cambio cualitativo hacia formas más brutales de expresión de la violencia. Menciona la existencia de maquinarias paralelas al Estado que le disputan el poder coercitivo y una cultura que "por naturaleza" es más violenta. Guillermo Valdés considera que se debe a un proceso de acumulación de la densidad criminal, a un incremento en el número de personas armadas y a la fragmentación de organizaciones criminales. En opinión de Natalia Mendoza, la intervención del Estado forzó a los grupos criminales a profesionalizarse y a hacerse más violentos, aunque puntualiza que otro factor que influyó en el escalamiento de la violencia fue el hecho de que se emprendiera una lucha contra estos grupos "por lo que son" más que "por lo que han hecho". Destaca que las políticas fueron dirigidas a exacerbar la rivalidad entre las organizaciones criminales, en lugar de que el Estado promoviera el acceso a la justicia y la solución de los conflictos dentro de la ley. ${ }^{1}$

Si bien comparto algunos de los argumentos que los especialistas en temas de seguridad citados han mencionado, en este trabajo me propongo ampliar la mirada hacia otros elementos no previstos en dichos comentarios y que, desde el punto de vista de las ciencias sociales, también pueden ayudarnos a comprender las raíces de los niveles de violencia actuales. Por otra parte, también me propongo incorporar la mirada de las ciencias sociales sobre algunos de los argumentos que ya se han propuesto para explicar los actuales niveles de violencia. De este modo, el presente trabajo desarrolla tres argumentos para explicar los actuales niveles de violencia

\footnotetext{
${ }^{1}$ Estos especialistas participaron en el debate conducido por Denise Maerker el 17 de septiembre de 2011 en Nexos, publicado bajo el título "Nuestra guerra: una conversación", en noviembre de 2011, en línea: <http://www.nexos.com.mx/?P=leerarticulov2 print $\&$ Article $=2102417>$.
} 
en nuestro país: a) la existencia de formas de violencia que han existido de tiempo atrás, que no se relacionan con las actividades de grupos de delincuencia organizada y que han sido toleradas e incluso ignoradas y cuyos efectos acumulados a lo largo del tiempo, sumados a otros factores coyunturales, han contribuido al actual escalamiento de la violencia; b) el debilitamiento y la descomposición - que tampoco han recibido una respuesta apropiada - de las instituciones de seguridad y procuración de justicia. Aunado a ello, las inapropiadas políticas de seguridad emprendidas con metas poco claras y llevadas a cabo de manera descoordinada por instituciones poco competentes y poco confiables, con escasa capacidad para investigar delitos y procesar a los responsables, han traído como consecuencia mayor impunidad, lo que a su vez ha propiciado un incremento de la criminalidad en general y de la violencia en particular, y c) insuficientes políticas sociales y económicas que reduzcan las desigualdades y promuevan la inclusión de amplios sectores que cada día ven reducidas sus expectativas de desarrollo, así como una mayor y mejor articulación e integración de estas políticas en torno a fines comunes con las políticas de seguridad.

\section{LAS VIOLENCIAS DE SIEMPRE}

Cuando los hombres sufren injustamente, es el sino de aquellos que son testigos de su sufrimiento avergonzarse de ello.

John Maxwell Coetzee (2006: 201-202).

En una de las compilaciones quizá más completas que se hayan elaborado sobre las reflexiones que han suscitado las manifestaciones de la violencia en diversos contextos históricos y sociopolíticos, los editores Nancy Scheper-Hughes y Philippe Bourgois comienzan diciendo que la violencia es un concepto escurridizo, puesto que en sí misma desafía una categorización fácil. Puede ser "todo o nada, legítima o ilegítima, visible o invisible, necesaria o inútil, sin sentido o gratuita, pero también altamente racional y estratégica" (Scheper-Hughes y Bourgois, 2004: 1-2). No obstante, y al igual que la locura, la enfermedad, el sufrimiento o la muerte, la violencia es, ante todo, parte de la condición humana, aunque sólo adquiere su poder y significado dentro de cada contexto social y cultural específico que es el que la dota de un determinado sentido.

Así, y a pesar de que nuestro país padeció inusitados niveles de violencia durante el periodo 2007 2011, la mayor parte de los esfuerzos de quienes cotidianamente nos informan de estos hechos se ha limitado de manera casi exclusiva a contar a los muertos o a documentar la forma en que han perdido la vida. En cambio, muy pocos esfuerzos se han dedicado a intentar comprender las causas, a descifrar el sentido, a explorar los factores sociales específicos que han permitido a la violencia escalar a sus actuales niveles más allá de los factores delincuenciales. Por ello, y con el fin de facilitar la comprensión del problema de la violencia que hoy afecta a nuestro país, intentaremos aportar algunos elementos que permitan situarla dentro de un contexto más amplio. Nos referiremos, en primer término, a la evolución histórica de las tasas de muerte por violencia en nuestro país, así como al lugar que ocupa México en relación con otros países por sus niveles de violencia. De igual forma, intentaremos brindar un breve panorama acerca de diferentes tipos de violencia que existen en nuestro país.

Históricamente, México siempre ha tenido elevadas tasas de muerte por homicidio. Si bien la tendencia principal durante el siglo $\mathrm{xx}$ fue la disminución sistemática de la tasa de homicidios por 100000 habitantes (véase cuadro 1), al mismo tiempo el homicidio no ha dejado de ocupar, desde entonces y hasta ahora, uno de los diez primeros lugares entre las causas de defunción en nuestro país. En efecto, las tasas por 100000 habitantes fueron cayendo a lo largo del siglo $\mathrm{xx}$ de la siguiente manera: 
Cuadro 1. Tasas de muerte por homicidio en México, 1930-1990

\begin{tabular}{cc}
\hline Año & Tasa por 100000 habitantes \\
\hline 1930 & 77.4 \\
\hline 1940 & 67.4 \\
\hline 1950 & 48.0 \\
\hline 1960 & 31.9 \\
\hline 1970 & 17.5 \\
\hline 1980 & 17.5 \\
\hline 1990 & 18.7 \\
\hline
\end{tabular}

Fuente: Kumate, Sepúlveda y Gutiérrez, 1993, Información en salud: la salud en cifras, Secretaría de Salud, México.

La tendencia se sostuvo durante los primeros años de este siglo, ya que la tasa fue de 14.7 en 2000 y de 11.1 en 2007 (CIDAC, 2009: 6). A partir de ese momento la tendencia descendente se detiene e inicia un ascenso inusitado que de nuevo ha llevado al país a una tasa de homicidios de 25 por 100000 habitantes $^{2}$ para 2011. Al comparar las tasas de muerte por violencia que existían en México en la década de los noventa - y que hoy hemos superado- con las de otros países, no podemos dejar de advertir que la nuestra es tres veces más alta que la de Estados Unidos, diez veces mayor que el promedio para los países de la Unión Europea y casi 20 veces más elevada que la de Japón o Corea (ops, 2003; UNODC, 2010). En realidad, nuestra tasa de muertes por homicidio es igual a la de la mayor parte de los países de Europa occidental hace más de tres siglos (Chesnais, 1992). Dentro del contexto regional de América Latina, tomando en cuenta que la región se distingue por tener las tasas más elevadas de muerte por homicidio en el mundo, México ocupa una posición intermedia. Pueden distinguirse tres grupos de países: los que tienen tasas de homicidio por debajo de la media mundial de 8.8 -Chile, Uruguay y Argentina—, los que tienen una violencia media - México, Paraguay y Ecuador- y aquellos con tasas que triplican o

\footnotetext{
2 Datos del Consejo Nacional para la Seguridad Pública y la Justicia Penal (Reforma, 16 de enero de 2012).
}

sobrepasan la media mundial -Colombia, Salvador, Guatemala, Brasil, Venezuela-. Cabe observar que los países con mayor violencia no son los más pobres, sino los más desiguales, tema que también retomaremos más adelante (Briceño-León, 2008).

Lo que proponemos es que las muertes que han tenido lugar durante los últimos años en el contexto de la lucha emprendida por el gobierno contra el crimen organizado han acaparado la atención e impedido visualizar otras violencias. De igual modo' y a pesar del cúmulo de evidencias que existen en la literatura especializada, en nuestro país se ha prestado muy poca atención a la manera como ciertas expresiones de la violencia, de manera significativa la violencia en la familia y en las instituciones, pueden estar vinculadas y propiciar otras formas de violencia. ${ }^{3}$ Scheper-Hughes y Bourgois destacan que han llegado a la conclusión, como lo han hecho numerosos estudios, de que la familia es una de las instituciones sociales más violentas. Sin embargo subrayan que a menudo los comportamientos violentos en las familias no son sino una respuesta a exclusiones sociopolíticas o económicas que hicieron parecer al comportamiento violento como el único posible dentro de las circunstancias (Scheper-Hughes y Bourgois, 2004: 3). Con el propósito de tener presentes esas otras formas de violencia, de las que se habla poco, mencionaremos algunas y proporcionaremos datos que nos den idea de su magnitud, a pesar de que permanecen invisibles porque las hemos "naturalizado", nos hemos acostumbrado a que formen parte de nuestra vida cotidiana.

El Informe Nacional sobre la Violencia y la Salud (Lozano et al., 2006) ofrece datos sobre los siguientes tipos de violencia: la que tiene por víctimas a niños y niñas, a jóvenes, a mujeres, a adultos mayores, la violencia sexual, el suicidio como forma de violencia autoinfligida, la que padecen los migrantes, la que ocurre en contextos institucionales como cárceles o psiquiátricos, la que resulta de la comisión de otros

\footnotetext{
${ }^{3}$ Véase la gran cantidad de referencias bibliográficas sobre este tema en el Informe Mundial sobre la Violencia y la Salud (ops, 2003).
} 
delitos y la que se produce en disputas por recursos naturales. Asimismo, existen otros estudios que han documentado la violencia en el noviazgo, en las escuelas, en el ámbito laboral, por motivos de preferencia sexual, los feminicidios y la que se genera por conflictos de origen étnico, político o religioso (véanse, entre otros, Arteaga y Valdés, 2010; Azaola, 2009).

Es importante destacar que, si bien los homicidios constituyen la expresión última de la violencia, sin duda la más severa e irreparable, representan apenas una proporción muy pequeña con respecto a otras manifestaciones de la misma. Esas otras formas de violencia también dejan huellas y ocasionan daños que pueden ser muy profundos y que alteran el curso de la vida de individuos, limitan o bloquean sus posibilidades de desarrollo, al mismo tiempo que afectan y tienen un impacto en la vida de la colectividad. Este impacto puede medirse, desde en términos económicos, hasta en daños físicos y emocionales, como lo han hecho diversos estudios en distintos países.

Cuadro 2. Tasas de muerte por homicidio por 100000 habitantes, Continente Americano, 2010

\begin{tabular}{lc}
\hline Canadá & 1.8 \\
\hline Chile & 3.7 \\
\hline Argentina & 5.5 \\
\hline Uruguay & 6.0 \\
\hline Costa Rica & 11.3 \\
\hline Paraguay & 11.5 \\
\hline Ecuador & 18.0 \\
\hline Estados Unidos & 5.0 \\
\hline Perú & 5.2 \\
\hline Brasil & 23 \\
\hline México & \\
\hline Colombia & 18 \\
\hline Venezuela & 33.4 \\
\hline El Salvador & 49 \\
\hline a Tasa correspondiente a 2009. & 66 \\
Fuente: United Nations Office on Drugs and Crime (UnDAC), 2010, \\
$\begin{array}{l}\text { Homicide Statistics-Latest Available Year, United Nations Office on } \\
\text { Drugs and Crime, en línea: }<\text { www.unodc.org }>.\end{array}$
\end{tabular}

Por ejemplo, el estudio de Scheper-Hughes destaca que la violencia estructural, es decir la de la pobreza, el hambre, la exclusión social y la humillación, inevitablemente se traduce en violencia doméstica e íntima (Scheper-Hughes, 2004: 1). También señala que la violencia no puede ser nunca entendida únicamente en términos físicos, según el uso de la fuerza, el asalto o el dolor que inflige. La violencia incluye siempre el asalto a la personalidad, a la dignidad y al sentido de valor de sí misma que tiene la víctima. Citaremos sólo algunos datos que ilustran la magnitud de algunos tipos de violencia. Un estudio realizado por la Comisión de Atención a Grupos Vulnerables de la Cámara de Diputados arrojó que entre 2007 y 2010 han perdido la vida en hechos de violencia 1600 menores de edad, mientras que aproximadamente 40000 han quedado huérfanos como resultado del enfrentamiento contra el crimen organizado (Excélsior, 1 de enero de 2011). Por su parte, el Instituto Nacional de Estadística y Geografía (INEGI) reporta la muerte por homicidio - no necesariamente vinculado con el combate al crimen organizadode un total de 3709 menores de edad durante el periodo 2006-2008. Asimismo, los datos del Sistema de Salud indican que durante el periodo de 1979 a 2004 dos menores de 14 años murieron cada día como consecuencia de la violencia familiar (Lozano et al., 2006).

Si miramos hacia la violencia autoinfligida, los datos de INEGI revelan que en 2007 ocurrieron en México más de 4500 suicidios. Casi 200 fueron cometidos por menores de 15 años, casi 1400 por jóvenes de entre 15 y 24 años y cerca de 1100 por jóvenes de entre 25 y 34 años. Son los jóvenes pobres, desempleados, sin oportunidades de inclusión escolar y sin expectativas de empleo quienes en mayor medida recurrieron al suicidio, aunque se calcula que por cada suicidio que se consuma hay ocho intentos fallidos (La Crónica de Hoy, 30 de agosto de 2009). En lo que se refiere a la violencia contra las mujeres, de acuerdo con el reporte "Feminicidio en México: aproximación, tendencias y cambios", presentado en el Congreso de la Unión en noviembre de 2011: 
después de que en 2007 la tasa de defunciones femeninas con presunción de homicidio se había reducido a la mitad respecto a los valores de 1985, en los dos últimos años (2007-2009) hubo un repunte de 68\%, es decir que durante este periodo se perdió el avance observado durante los 23 años anteriores. En efecto, mientras que en 2007 hubo 1 085, en 2009 hubo 1858 defunciones de mujeres con presunción de homicidio (Reforma, 23 de noviembre de 2011).

Un estudio realizado en 2009 a una muestra representativa de 23000 niños y niñas de escuelas públicas de educación básica a nivel nacional arrojó que $65 \%$ de los alumnos dijeron haber recibido al menos una agresión física en su escuela durante los dos últimos años y la mayoría reportó uno o más incidentes de violencia psicológica. A la pregunta: “QQué cambiarías en tu escuela?", $6 \%$ de los niños y niñas respondieron de manera espontánea "que no hubiera tanta violencia" y $18 \%$ de las niñas reportaron haber sufrido intentos de abuso sexual por parte de sus compañeros (Azaola, 2009).

Lo que hemos intentado mostrar en este primer argumento sobre el origen de la violencia en nuestro país es que - tal como lo muestran con claridad Scheper-Hughes y Bourgois- hay una violencia que se considera "normal", de todos los días, que a menudo es pasada por alto, mientras que hay otra violencia a la que se considera "extraordinaria, patológica, excesiva o gratuita". Lo importante, sin embargo, es que lejos de existir una ruptura entre ambos tipos de violencia, lo que existe es más bien una continuidad entre lo que los autores denominan "la violencia política y la criminal" o, si se quiere, entre "las patologías del poder, individuales y
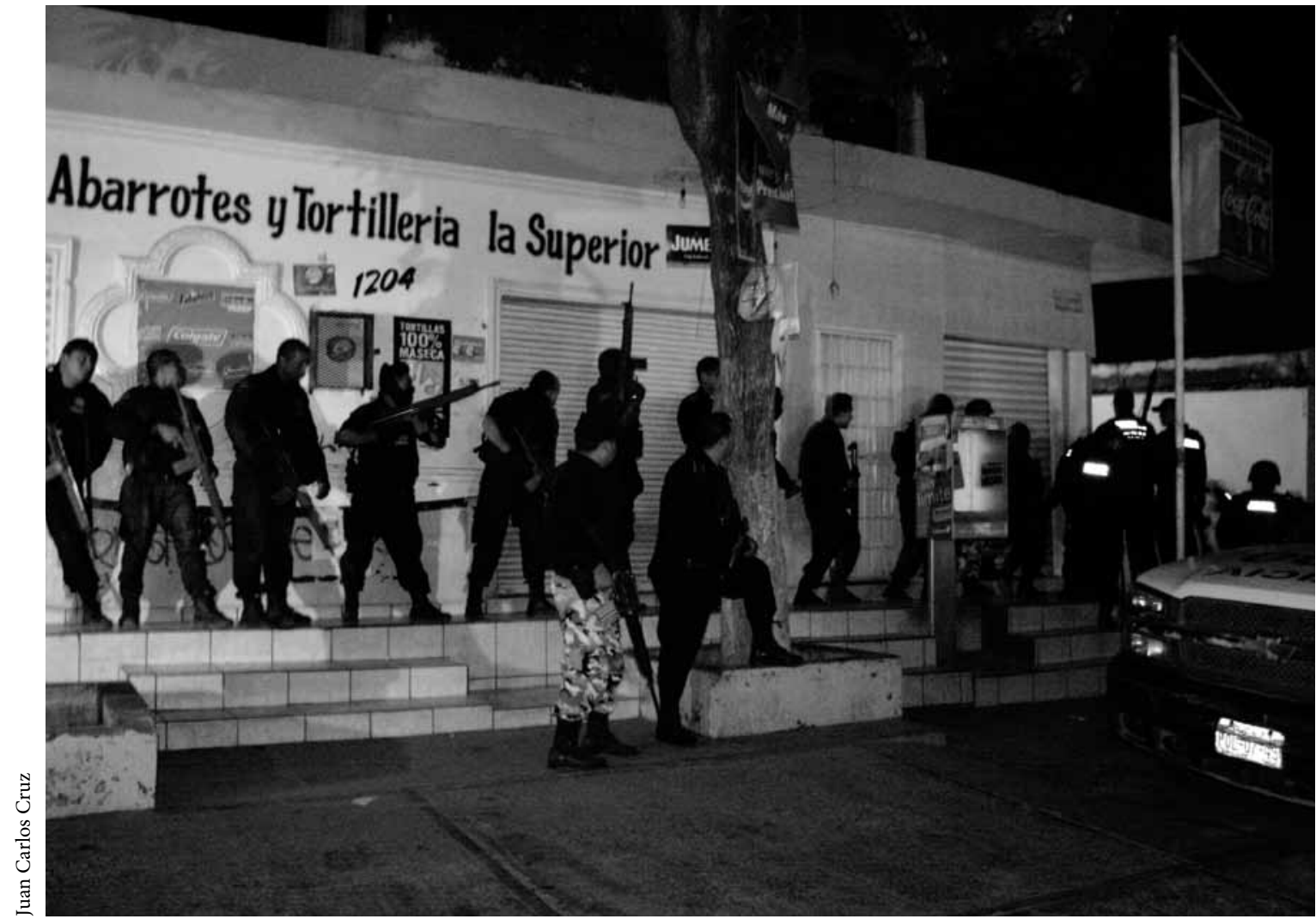

Policías se resguardan durante un enfrentamiento contra un grupo de gatilleros en la colonia Las Vegas, Culiacán, Sinaloa, 2008. 
colectivas" (Scheper-Hughes y Bourgois, 2004: 5). Esto también significa que si queremos encontrar las claves de la violencia que hoy padece nuestro país, no podemos seguir ignorando los vínculos de esas violencias que hemos experimentado de tiempo atrás, que hemos pasado por alto y normalizado, puesto que es muy posible que sin esas formas de violencia no se habrían producido las que hoy acaparan nuestra atención, no habrían encontrado un terreno fértil para reproducirse o no habrían escalado a los niveles que hoy observamos. En síntesis, éste es nuestro primer argumento. Lo que pretendemos mostrar en nuestro segundo argumento es que también existe continuidad entre las violencias de todos los días y la violencia ocasionada tanto por la criminalidad como por las políticas del Estado que intentan reducirla. Veremos algunos datos que nos permitirán sostener este argumento.

\section{LA VIOLENCIA DEL CRIMENY LA DE LAS POLÍTICAS QUE INTENTAN CONTENERLO}

Por cada persona que caiga en esta guerra, por cada persona que muera mientras yo mismo siga vivo, deberá encenderse en mí un pensamiento. De no ser así, ¿qué otras velas tendría? No los conozco, pero son más que parientes para mí.

Elias Canetti (2010: 19).

El segundo argumento que intentamos construir sostiene que la violencia es el resultado tanto del incremento de la criminalidad como de las políticas que lejos de contenerla han contribuido a exacerbarla. El gobierno ha sostenido que era preciso emplear toda la fuerza, incluida la del Ejército, para enfrentar al crimen organizado y contener a los grupos delictivos y sostuvo, también, que sus políticas estaban encaminadas a reducir el tráfico y el consumo de drogas, a recuperar los espacios públicos y a fortalecer las instituciones del Estado y devolver la confianza de los ciudadanos en ellas. Veremos cuáles han sido los resultados de estas acciones cinco años después de que iniciara su ejecución (Presidencia de la República, 2007; ssp, 2007).

Según el estudio "Barómetro de conflictos 2010" de la Universidad de Heidelberg, Alemania, la violencia en México se compara con la de Iraq, Somalia o Sudán, donde "la fuerza bruta se utiliza constantemente, de una forma organizada y sistemática" (Reforma, 12 de enero de 2011). En 2009, Ciudad Juárez y Nogales fueron consideradas "las ciudades más violentas del mundo" por tener tasas de muerte por violencia de 201 y 255 por 100000 habitantes, respectivamente, mientras que siete ciudades fronterizas registraron una tasa promedio de 75 homicidios por cada 100000 habitantes (Reforma, 10 de enero de 2010). La Procuraduría General de la República (PGR), en su "base de datos de fallecimientos por presunta rivalidad delincuencial" - rótulo que revela la intención de responsabilizar de la violencia sólo a los grupos delictivos, dejando fuera la intervención de las instituciones del Estado- proporcionó los siguientes datos:

Cuadro 3. Fallecimientos por presunta rivalidad delincuencial, 2006-2011

\begin{tabular}{lc}
\hline 2006 & 62 \\
\hline 2007 & 2826 \\
\hline 2008 & 6838 \\
\hline 2009 & 9614 \\
\hline 2010 & 15273 \\
\hline 2011 (enero-sept.) & 12903 \\
\hline
\end{tabular}

Fuente: Procuraduría General de la República (PGR), 2011, "Fallecimientos por presunta rivalidad delincuencial, 2006-2011”, Procuraduría General de la República, en línea: <www.pgr.gob.mx>.

Con los datos anteriores, más la estimación de la misma Procuraduría de que el incremento entre 2010 y 2011 habría sido de $11 \%$, es posible señalar que el número total de muertes en 2011 fue de aproximadamente 17000 , lo que daría un total de casi 52000 muertes de diciembre de 2006 a diciembre de 2011. 
Se trata de un incremento abrumador de $600 \%$ si se comparan sólo los resultados del primero con el quinto año de gobierno. Es un incremento atípico para cualquier delito, pero por encima de todo se trata, posiblemente, ${ }^{4}$ de la mayor pérdida de vidas humanas que históricamente haya tenido lugar en el contexto de una política dirigida por el Estado contra el crimen organizado - etiqueta que se utilizaba para informar sobre estas muertes antes de que se resolviera rotularlas como el resultado sólo de la "rivalidad delincuencial" -.5

La violencia ha afectado principalmente a los jóvenes. De acuerdo con datos del INEGI, el homicidio es la primera causa de muerte entre los jóvenes. Entre 2007 y 2009 , el homicidio de adolescentes de 15 a 19 años creció $124 \%$, el de los jóvenes entre 20 y 24 años en $156 \%$ y el de los jóvenes entre 25 y 29 años en $152 \%$. Con ello se revirtió la tendencia decreciente que la muerte por homicidio entre los jóvenes había observado durante el periodo 2000-2007 (Presidencia de la República, 2011: 101). El suicidio,

por su parte, ocupó el tercer lugar entre las causas de muerte entre los jóvenes, pasando de una tasa de 5.8 por cada 100000 jóvenes en 2000 a una de 9.4 en 2010 (El Universal, 12 de septiembre de 2011). Existen otros resultados igualmente dolorosos y preocupantes. Es el caso de las personas "desaparecidas". Hasta noviembre de 2011, la Comisión Nacional de Derechos Humanos (CNDH) señaló que le habían sido reportadas como "desaparecidas" 16782 personas, algunas de ellas clasificadas como "extraviadas" y otras como "fallecidas no identificadas" (La Crónica de Hoy, 29 de noviembre de 2011). En el caso de los migrantes "secuestrados", sólo en 2010 se estimaron en 20000 , es decir, un promedio

\footnotetext{
${ }^{4}$ No conocemos casos semejantes en cuanto a pérdida de vidas humanas por el mismo motivo. Recordemos que la violencia que tuvo lugar en Colombia obedeció a distintos órdenes de conflictos: guerrilla, rivalidad entre grupos políticos, narcotráfico, paramilitarismo, etcétera.

${ }^{5}$ En enero de 2011, incluso la página electrónica de la Presidencia (<www.presidencia.gob.mx/voceria-seguridad/>) las llamaba "muertes originadas en el combate al crimen organizado".
}

de 55 al día, de acuerdo con el presidente de la CNDH (Reforma, 7 de enero de 2011).

La Auditoría Superior de la Federación (ASF) ha hecho severos cuestionamientos en relación con los recursos invertidos en seguridad y los resultados alcanzados. Según sus informes, es posible constatar que durante la administración de Felipe Calderón el gasto público en seguridad se ha incrementado, hasta 2010, siete veces en comparación con el sexenio anterior: "Sin embargo, no existen resultados evidentes del impacto real que han tenido estos recursos en materia de seguridad y justicia penal" (México Evalúa, 2011: 4). Aun más, el gasto de 197000 millones de pesos en seguridad pública para 2010 representó prácticamente la misma cantidad - $93 \%$ - que el gasto dirigido a educación pública y superó el monto asignado a los ramos de salud y desarrollo social. De igual modo, y a pesar de que la Secretaría de Seguridad Pública (ssP) obtuvo un incremento de $71 \%$ en promedio anual en su presupuesto durante el periodo 2006-2009, los delitos más sensibles para la sociedad no disminuyeron durante el mismo periodo: el secuestro registró un incremento de $83 \%$, seguido por los homicidios dolosos $-34 \%$ - y el robo con violencia - 31\%- (México Evalúa, 2011: 18). El informe de la ASF de 2009 también señala que, no obstante que la Policía Federal multiplicó por cuatro el número de elementos que tenía en 2001, los logros de 14 operativos efectuados en entidades con mayor presencia del crimen organizado fueron poco significativos y ello también a pesar de que el total de policías municipales, estatales y federales en el país fue de 514 638, es decir, $5.2 \%$ superior al número de policías con que se contaba en 2008.

Llama la atención la cantidad de recursos y el despliegue de fuerzas empleados para detener a un elevado número de personas que no llegan a ser procesadas ni sentenciadas. Por ejemplo, mientras que el Cuarto Informe de Gobierno da testimonio de que durante el periodo de enero de 2007 a junio de 2010 se detuvieron a 113000 personas presuntamente vinculadas con el narcotráfico, al mismo tiempo destaca 
que durante el mismo periodo los juzgados federales sólo dictaron 735 sentencias de última instancia por delitos relacionados con la delincuencia organizada. Asimismo, un informe de la PGR indica que de diciembre de 2006 a junio de 2011 fueron capturados un total de 3226 presuntos responsables por el delito de delincuencia organizada, de los que sólo fueron presentados 1 186, es decir, 37\% (Reforma, 7 de noviembre de 2011). Por su parte, la ssp informó que sólo 3\% de las personas detenidas por la Policía Federal durante la actual administración están vinculadas con grupos del crimen organizado que operan en el país, ya que el resto son "infractores aislados" (La Crónica de Hoy, 16 de enero de 2012).

También el reciente informe de Human Rights Watch (HRW) destaca de manera contundente que a pesar de que durante la presente administración han ocurrido más de 45000 muertes en el contexto de la guerra contra el narcotráfico, la PGR sólo ha iniciado 997 averiguaciones previas por este tipo de homicidios, ha consignado a 343 personas y ha obtenido únicamente 22 condenas en contra de los responsables (HRW, 2011). Los datos anteriores, entre muchos otros, constatan los graves niveles que han alcanzado la impunidad y la falta de competencia para investigar y perseguir los delitos por parte de las instituciones de seguridad y procuración de justicia del país. Esto explica que la violencia siga escalando, pues pone de manifiesto la incapacidad del Estado para ejercer de manera legal y legítima el monopolio del uso de la fuerza. Basta señalar que la impunidad para todos los delitos que son denunciados a nivel nacional fue de $98.7 \%$ en 2007 , lo que hace de México uno de los países con mayor impunidad (CIDAC, 2009), mientras que $80 \%$ de los homicidios quedaron impunes en 2008 (México Evalúa, 2009).

La situación es todavía más grave en algunas ciudades pues, de acuerdo con un estudio del Consejo Nacional para la Seguridad Pública y la Justicia Penal, mientras que en 13 ciudades con los más altos índices de violencia se cometieron 9797 homicidios en 2010, sólo se reportaron 406 sentencias condenatorias, lo que implica una impunidad de 96\% (Reforma, 16 de enero de 2012). En lo que se refiere a la participación del Ejército en las labores de combate al crimen organizado, el informe de HRW señala que hasta mediados de 2010 se habían iniciado 3671 investigaciones por violaciones de derechos humanos cometidas por el Ejército, de las que sólo se habían obtenido 29 sentencias. Sin embargo, el secretario de la Defensa Nacional declaró en un informe presentado ante el Senado a finales de 2011 que al momento había 167 militares indiciados, 89 procesados, nueve sentenciados y 11 prófugos $(E l$ Universal, 10 de noviembre de 2011). Estos números contrastan con las 4772 quejas por violaciones a derechos humanos contra el Ejército que había recibido la CNDH hasta 2010, lo que representa un incremento de $400 \%$ si se compara con las 376 quejas recibidas durante 2007 y con las 1644 de 2009.

Asimismo, la CNDH reportó haber recibido 11680 quejas en total contra las secretarías de la Defensa Nacional, de Marina, de Seguridad Pública y de la PGR de diciembre de 2006 a diciembre de 2011. La mayoría de las quejas son por tratos crueles, inhumanos o degradantes, irregularidades en cateos, detenciones arbitrarias y violaciones a derechos de los migrantes. La Comisión destacó que todos los días agentes federales y militares realizan en promedio tres cateos ilegales a domicilios de ciudadanos, aunque precisó que la cifra puede ser más elevada, pues este número corresponde sólo a los casos denunciados y la mayor parte de los casos no son denunciados (El Universal, 23 de diciembre de 2011; La Crónica de Hoy, 30 de noviembre de 2011).

En las más de 90 recomendaciones que la $\mathrm{CNDH}$ ha dirigido a la Secretaría de la Defensa Nacional durante los últimos años, le ha solicitado adoptar, entre otras, las siguientes medidas: a) elaborar un reglamento que fije los protocolos del uso de la fuerza de los militares en operativos de seguridad pública, así como los de detención de civiles; b) cesar las detenciones arbitrarias, cateos ilegales y abusos de autoridad; c) emitir una directiva que regule el uso proporcional de la fuerza pública, contemplando los 
principios de legalidad, necesidad y proporcionalidad; d) emitir una circular $u$ ordenanza dirigida a los mandos superiores, medios y a los elementos de tropa para que se garantice que las personas que sean detenidas en los operativos no sean trasladadas a instituciones militares, sino que sean puestas de inmediato a disposición de la autoridad civil correspondiente, ye) emitir instrucciones a efecto de que las fuerzas armadas, de forma inmediata, cesen las detenciones arbitrarias bajo una supuesta ejecución de solicitudes de apoyo y colaboración en la investigación, localización y presentación formuladas por las autoridades ministeriales, y exijan la debida fundamentación y motivación a dichas autoridades.

Cabe señalar que la presencia de agentes del Estado en los operativos conjuntos para enfrentar a la delincuencia organizada aparece, de acuerdo con Fernando Escalante (2011), como uno de los factores más claramente asociados al brutal incremento de la violencia que ha tenido lugar en el periodo 20082010. Escalante argumenta que en los estados del

noroeste donde hubo operativos conjuntos la tasa de homicidios se disparó en línea prácticamente vertical a partir del segundo año de los operativos. Si bien no deja de notar que las tasas han aumentado en casi todo el territorio nacional, apunta que las más elevadas aparecen en los estados en que ha habido operativos conjuntos "de alto impacto" (Escalante, 2011).

Respecto de la violencia cometida por agentes del Estado, un estudio realizado sobre el tema en América Latina distingue tres tipos de violencia ejercida por el Estado: 1) la que tiene lugar para enfrentar al delito y se ejerce dentro de los márgenes de la ley; 2) la que enfrenta al delito sobrepasando los marcos legales vigentes, por ejemplo, mediante la tortura o las ejecuciones extrajudiciales, y 3 ) la violencia de carácter abiertamente criminal ejercida por agentes del Estado que se valen de su investidura para cometer y encubrir actos criminales (Cruz, 2010). La violencia criminal ejercida por el Estado en este último caso tiene a menudo su origen en estructuras legales e ilegales que originalmente fueron creadas para combatir de manera extraordinaria al crimen organizado, pero que con el tiempo degeneraron en mafias del crimen organizado tan violentas como los grupos que debían combatir. Se trata de grupos que no sólo van acumulando experiencia en la lucha contra el crimen, sino también conocimiento y conexiones que utilizan luego para cometer delitos (Cruz, 2010). Como ejemplo, en México puede citarse el caso de Los Zetas, grupo originalmente conformado por desertores del Ejército, o el de "La Línea”, creado por narcotraficantes que lograron controlar a la policía de Ciudad Juárez.

No es posible pasar por alto que si bien la violencia criminal es causada por narcotraficantes, bandas del crimen organizado, pandilleros y ciudadanos comunes, hay otra parte importante que es provocada por agentes del Estado. Pero el Estado y sus instituciones, de acuerdo con el estudio mencionado, no son actores corrientes en la dinámica de la violencia: no es lo mismo un asesinato cometido por un ciudadano común que uno perpetrado por un policía, no es lo mismo una red de extorsión o secuestro conducida por una banda del crimen organizado que una formada por policías, y no es lo mismo una operación de narcotráfico encubierta por una empresa que una protegida por un agente o un comando militar. La participación de agentes estatales en actividades delincuenciales amplía las repercusiones del delito, convierte a las instituciones en cómplices de la violencia, reproduce la impunidad y mina la confianza de los ciudadanos, con lo que se afecta la legitimidad del régimen (Cruz, 2010).

De manera similar, otro estudio realizado por el International Centre for Science in Drug Policy (ICSDP) - dedicado a reunir la información disponible basada en evidencia científica con el fin de reducir los daños asociados a las políticas relacionadas con las drogas - analizó el impacto que los operativos de combate a las drogas en diversos países han tenido sobre el incremento o la reducción de los niveles de violencia. Contrario a lo que originalmente habían supuesto, el estudio demostró que $87 \%$ de las investigaciones que cuentan con evidencia científica 
rigurosa muestran que los operativos han elevado los niveles de violencia y concluyen que la evidencia científica disponible apunta claramente a que multiplicar la intensidad de los operativos contra las drogas no reduce, sino que incrementa los niveles de violencia (ICSDP, 2010).

Mark Kleiman, desde la premisa de que la posibilidad de legalizar el comercio de drogas o de eliminar su consumo no parece estar cerca, advierte que lo más conveniente es adoptar políticas que reduzcan los daños ocasionados por las políticas de criminalización. Apunta que el hecho de que la mayoría de los distribuidores no sean violentos genera una oportunidad estratégica, pues si los gobiernos se enfocaran sólo en perseguir y llevar a prisión a los más violentos podrían obtener el doble beneficio de incapacitar a quienes producen los daños más severos y disuadir al resto, no de distribuir drogas, sino de cometer actos de violencia. Políticas de este tipo podrían al menos reducir la violencia y el desorden (Kleiman, 2011: 98).

$\mathrm{Al}$ desarrollar este segundo argumento hemos intentado mostrar que el saldo que ha dejado la violencia delictiva, así como la provocada por las políticas que han pretendido combatirla, es muy grave tanto por el número y los daños sufridos por las víctimas directas - muertos, desaparecidos, secuestrados, heridos, incapacitados, desplazados, detenidos injustamente, extorsionados, etc.-, como por los ocasionados a las víctimas indirectas. En este último caso, los huérfanos, las viudas y otros familiares también han sufrido pérdidas y daños de todo tipo que no han sido visibilizados y cuyos efectos y consecuencias se agravan en la medida en que el Estado

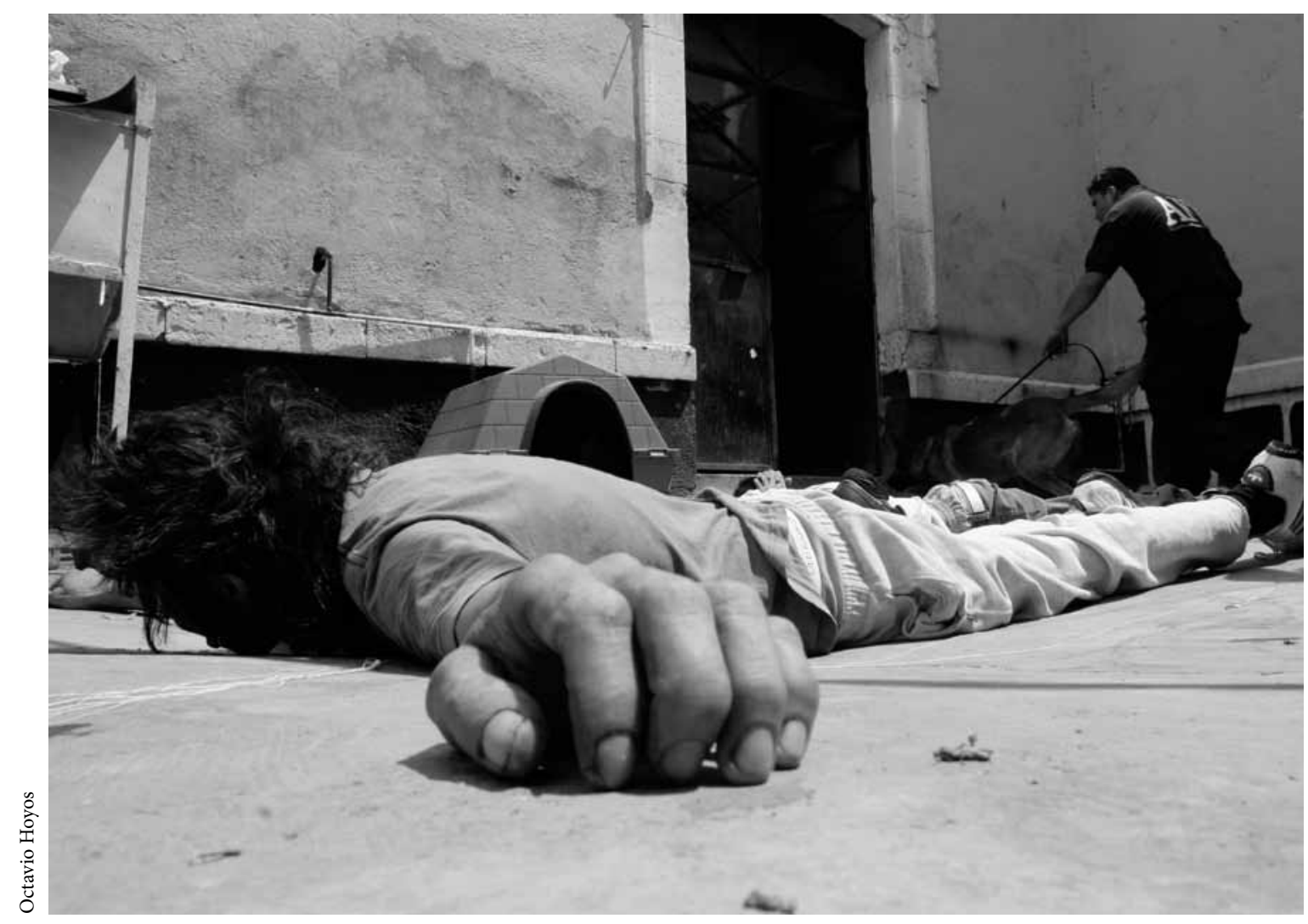

Detenciones a narcomenudistas en el Barrio de Tepito, ciudad de México, 2007. 
no ha reconocido su responsabilidad ni el derecho que les asiste.

Para concluir esta parte quisiera volver al texto de Scheper-Hughes y Bourgois. Ellos puntualizan que la violencia que cometen los militares y los cuerpos de seguridad suele considerarse como "legítima", a diferencia de aquellos actos que, siendo de la misma naturaleza, cometen quienes protestan o se rebelan y que suelen percibirse como "ilegítimos". Es decir que ciertos actos pueden ser considerados gloriosos o depravados, dependiendo de la posición política de quien los ejecute o los califique. Los mismos actos pueden ser vistos como actos de mártires o de terroristas, lo que sirve para recordarnos que es la cultura la que moldea las expresiones de la violencia, así como su exaltación o su condena (Scheper-Hughes y Bourgois, 2004: 2). Los autores destacan que en muchos casos los actos más violentos son conductas socialmente permitidas e incluso son alentadas o se les disfruta como un derecho o un deber moral.

En resumen, nuestro segundo argumento apunta a que la violencia que hoy padecemos no puede atribuirse sólo a las actividades de grupos delictivos, sino que al menos una parte de la responsabilidad de la situación imperante recae también sobre las instituciones y las políticas gubernamentales que han intentado contenerlos. Más aún, consideramos que los efectos que tiene la violencia cuando es ejercida por autoridades que actúan al margen de la ley no pueden ni deben ser medidos sólo en términos cuantitativos, como suele hacerse cuando se arguye que son más los homicidios perpetrados por delincuentes, puesto que acerca de éstos sabemos dónde están colocados y qué cabe esperar. En cambio, cuando son las autoridades las que pasan por encima de la ley los efectos son mucho más severos y corrosivos, ya que sus actos subvierten los principios en que se funda el pacto social, ponen en cuestión la legitimidad del poder, minan la confianza y la credibilidad de los ciudadanos y en último término destruyen los cimientos que hacen posible la cohesión social.

\section{LA VIOLENCIA DE LA EXCLUSIÓN}

\author{
Si la libertad significa algo, es decirles \\ a los demás lo que no quieren oír.
}

George Orwell (2001).

Una vez más, es el texto de Scheper-Hughes y Bourgois el que nos alerta acerca de que, mientras ciertos actos de violencia tienden a deslumbrarnos, a atraer nuestra atención, otros, en cambio, los pasamos por alto puesto que forman parte de "la violencia de todos los días": la de la mortalidad infantil, la desnutrición, la enfermedad, la injusticia y la humillación que tocan a los socialmente marginados con mucha mayor frecuencia. Éstas son formas de violencia no reconocidas, invisibles, puesto que las desigualdades estructurales tienden a ser "naturalizadas" (Scheper-Hughes y Bourgois, 2004: 2, 5). Nuestro tercer argumento sostiene que una de las raíces de la violencia que padecemos tiene que ver con la insuficiencia de políticas sociales y económicas para reducir las desigualdades y las injustificables distancias y para promover la inclusión de amplios sectores, que cada día ven reducidas sus expectativas de desarrollo. Asimismo, ha hecho falta una mayor y mejor articulación e integración de las políticas sociales y económicas con las de seguridad en torno a fines comunes capaces de generar un consenso social. En otros términos, como veremos más adelante, ha faltado lo que algunos analistas han denominado "un buen gobierno", capaz de conquistar y conducir la confianza de los ciudadanos. En los términos en que alguna vez lo expresara Carlos Pascual:

La seguridad no puede ser un fin en sí mismo, sino que debe ser una condición que permita a las comunidades lograr normalidad y prosperidad. [...] Las familias que han sufrido altos grados de violencia o crimen buscan no sólo un ambiente más seguro, sino también mandar a sus hijos a buenas escuelas, viajar libremente y tener certeza laboral. Los programas 
de seguridad deben estar integrados con programas sociales y económicos, y el éxito debe medirse con indicadores sociales, además de la reducción de la violencia y el crimen (Pascual, 2010: 10).

Algunos indicadores muestran que los déficit de las políticas sociales y económicas se han acumulado, lo que indudablemente ha contribuido a la expansión de los mercados informales e ilegales. Por ejemplo, el gobernador del Banco de México (Banxico) informó en enero de 2012 que mientras en nuestro país se requiere generar un millón de empleos al año, durante ese año se crearían sólo la mitad de ellos si se lograba un ritmo de crecimiento de entre 3 y $4 \%$ (Banxico, 2012). De igual modo, según la Organización para la Cooperación y el Desarrollo Económicos (OCDE) nuestro país ocupa el segundo lugar en desigualdad, puesto que el promedio de ingreso de $10 \%$ de la población más rica es 26 veces mayor que el ingreso de $10 \%$ de la población más pobre, cuando en otros países miembros la diferencia es de nueve veces (oCDE, 2011).

De acuerdo con el informe de la Comisión Económica para América Latina y el Caribe (CEPAL) "Panorama Social de América Latina 2011", México y Honduras fueron los únicos países cuyas tasas de pobreza se elevaron, mientras que varios países latinoamericanos la redujeron de manera significativa. En el caso de México, la proporción de personas en situación de pobreza pasó de 34.8 a 36.3 entre 2008 y 2010, en tanto que la de personas en situación de indigencia subió de 11.2 a 13.3\%. A decir de Alicia Bárcena, secretaria ejecutiva del organismo, "la tarea pendiente de México es la diversificación productiva, ampliar más su posibilidad de inserción en cadenas globales de valor, potenciar su mercado interno y mejorar la calidad del empleo" (Reforma, 30 de noviembre de 2011).

Magdy Martínez-Solimán, representante del Programa de las Naciones Unidas para el Desarrollo (PNUD), informó que en un año México perdió 23\% en su nivel de desarrollo humano, al retroceder 15 lugares en cuanto a la distribución de la riqueza $(\mathrm{La}$
Jornada, 3 de noviembre de 2011). Asimismo, de acuerdo con datos del INEGI, el ingreso promedio de los hogares mexicanos cayó $12.3 \%$ en 2010 respecto de 2008. Es necesario tener en cuenta otro dato, en particular para las ciudades fronterizas: de enero de 2008 a junio de 2011, los estados de la frontera norte han recibido un promedio de 500000 mexicanos deportados por año y de 300000 deportados de otras nacionalidades en el mismo lapso. Esto significa que algunas ciudades reciben hasta 200 personas deportadas diariamente (Reforma, 15 de enero de 2011).

Todos estos datos son importantes puesto que, como muestra con claridad un estudio elaborado por el Banco Mundial (BM), la disparidad en el ingreso es un factor crucial para explicar los niveles de criminalidad. El estudio recoge una gran cantidad de datos de distintos países que constatan que a mayor desigualdad, mayor será el número de homicidios dolosos y de robos (вм, 1998). De la misma manera, un estudio del Banco Interamericano de Desarrollo (вID) plantea que la explosión en los niveles de violencia en Latinoamérica tiene su origen en un conjunto de factores complejos que operan en el nivel individual, familiar, comunitario y social, aunque la desigualdad es una de las constantes (BID, 1999).

Como lo había hecho notar el Informe Mundial sobre la Violencia y la Salud, existe una correlación entre violencia y desigualdad, no entre violencia y pobreza: los países más igualitarios tienen menores tasas de violencia (ops, 2003: 40). También un informe del PNUD había hecho hincapié en que no es lo mismo ser pobre en una sociedad parejamente pobre, que serlo en sociedades duales donde coexisten niveles de vida como los de Ginebra y Burundi al mismo tiempo. La tensión que se genera en estas sociedades es muy alta y produce la sensación de que no hay un "juego limpio", lo que repercute en la confianza que se deposita en las instituciones. Las grandes desigualdades son un destructor del capital social: crean desconfianza, cinismo, falta de interés en la asociatividad y apatía. A su vez, la falta de confianza mina la legitimidad y reduce los márgenes de 


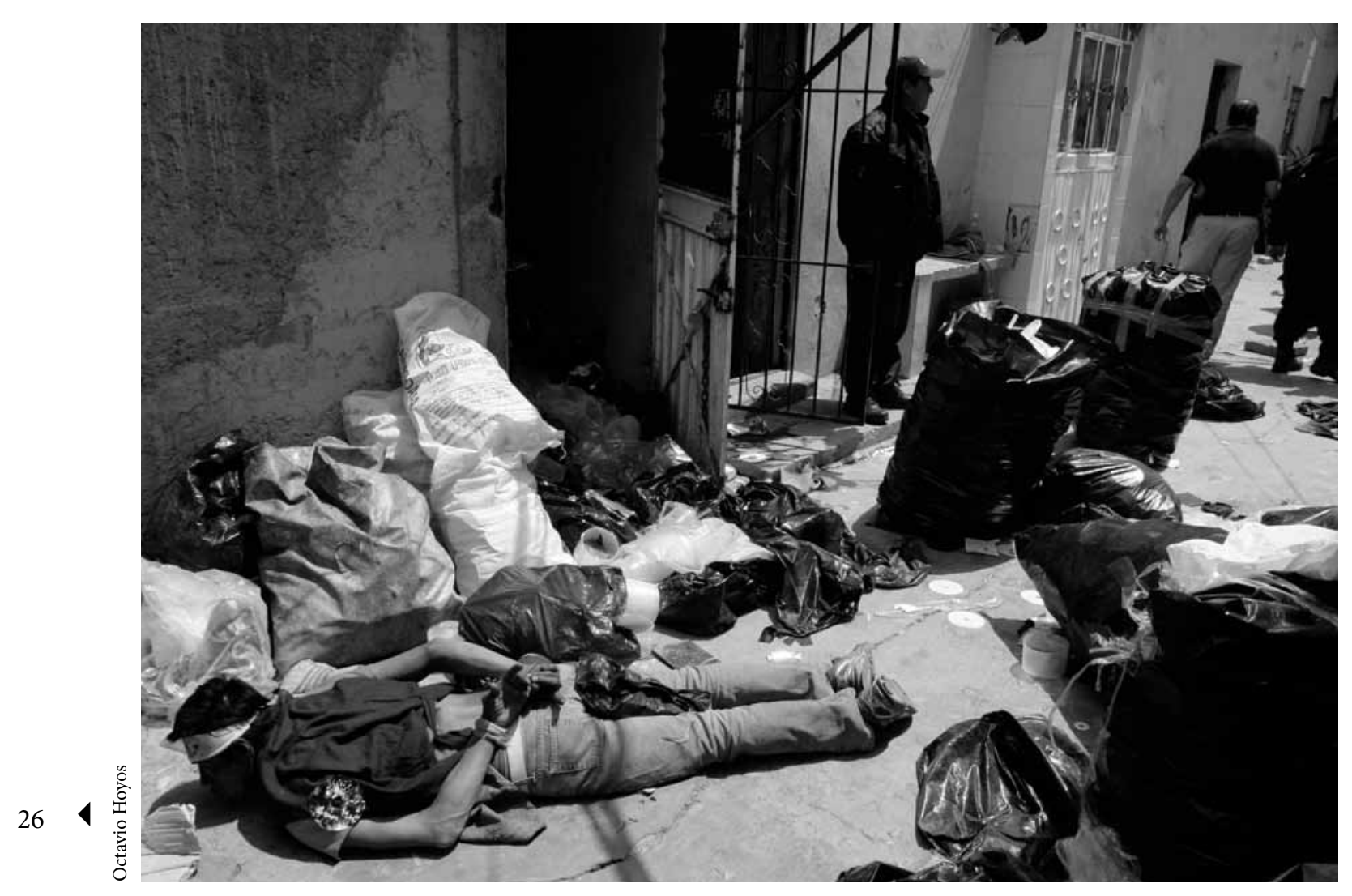

Operativo de cateo en el Barrio de Tepito, ciudad de México, 2007.

gobernabilidad democrática. De ahí que el PNUD recomiende crear las condiciones para que la sociedad esté convencida de que vive en un marco de "juego limpio" (PNUd, 2007).

La exclusión de amplias capas de la sociedad, en particular de oportunidades de educación y empleo, es otro factor que propicia manifestaciones de violencia. Es preciso tomar en cuenta que, de acuerdo con el Consejo Nacional de Población (Conapo), 3.7 millones de menores de 17 años no acudieron a la escuela en 2010 y 7 millones de jóvenes de 18 a 29 años no estudiaban ni trabajaban. Otro estudio reciente llevado a cabo en varias ciudades de nuestro país por la Comisión Nacional para Prevenir y Erradicar la Violencia Contra las Mujeres (CNPEVM) destaca que los jóvenes carecen de estímulos para seguir estudiando porque no encuentran oportunidades de empleo calificado. Incluso la precarización de las ocupaciones en el sector formal constituye un elemento de desaliento para ocuparse en ellas, por lo que los jóvenes optan por migrar o por insertarse en actividades informales o delictivas. De modo que en las nuevas generaciones ya no se concreta la trayectoria de obtener un certificado educativo-ingresar a un empelo formal-acceder a los beneficios de la seguridad social-formar una familia (CNPEVM, 2010: 9-10).

La inclusión de los jóvenes es un tema fundamental. La premisa básica, una de las más sólidas teorías del control social, es que aquellos que cometen actos delictivos lo hacen como resultado de los débiles vínculos que mantienen con la sociedad. Esta teoría sostiene que la mayoría de las personas 
obedece las leyes, no por el temor a las sanciones que podrían eventualmente recibir, sino como resultado de los lazos de afecto que los unen con aquellos que resultarían lastimados por sus actos, esto es, por el daño que el delito ocasionaría a sus expectativas para el futuro. De ahí que quienes tienen un débil lazo de apego hacia los otros o perspectivas limitadas de alcanzar logros en el futuro son más propensos a vivir el momento y a cometer delitos. El futuro no cuenta porque tiene un valor escaso para ellos (Hirschi, 2002).

Roberto Briceño-León, al analizar los niveles de violencia en América Latina, postula que hay un conjunto de factores permanentes que inciden sobre la violencia que tienen que ver con las condiciones sociales y económicas de la región y otro grupo de tipo circunstancial que se relaciona con la legitimidad institucional, las condiciones políticas y el pacto social. Briceño-León observa que los logros más significativos se han obtenido cuando se ha conseguido intervenir en los factores que afectan la legitimidad institucional. Ello muestra que la violencia no es una condición irreversible. Se trata de condiciones sociales y políticas que pueden ser alteradas para bien o para mal, como lo ilustran los casos de Colombia - al haber reducido sus niveles de violencia- y de Venezuela - al haberlos incrementado(Briceño-León, 2008).

Asimismo, otros estudios han señalado que la calidad de las condiciones de buen gobierno en un país, en cuanto al marco legal y las políticas que ofrecen protección social, es un factor determinante de los niveles de violencia. En particular, el grado en que una sociedad hace cumplir las leyes existentes sobre la violencia al detener y encausar a los delincuentes puede actuar como factor disuasivo contra la violencia (ops, 2003: 41). Por ejemplo, en Sudáfrica un estudio mostró que, después del apartheid, la impunidad para los que habían cometido abusos contra los derechos humanos y la incapacidad de la policía de cambiar significativamente sus métodos han contribuido a un sentimiento generalizado de inseguridad y han incrementado el número de acciones extrajudiciales que hacen uso de la violencia (Aitchinson, citado en ops, 2003: 41). Por su parte, Carlos Flores anota:

\begin{abstract}
el monopolio fáctico de la violencia sólo se hace tolerable cuando [el Estado] da muestras claras de proteger al menos un umbral básico de intereses públicos y cuando los distintos elementos que integran la comunidad política no están sistemática y permanentemente excluidos de la posibilidad de beneficiarse de los recursos sociales disponibles (Flores, 2011).
\end{abstract}

De ahí que este autor sostenga que la violencia que observamos en México:

no es sino la derivación más grave de un problema más profundo: la disfuncionalidad estructural de un Estado en el que sus premisas y mecanismos esenciales de funcionamiento se encuentran desprovistos de contenidos básicos de interés público (Flores, 2011).

En el mismo sentido, un estudio realizado por el Instituto Holandés para la Democracia Multipartidaria hace notar que en muchos países y específicamente en América Latina se percibe cada vez más a los políticos y a los partidos como parte de las redes ilícitas y corruptas, lo que ha incrementado la desconfianza pública hacia las instituciones estatales y ha dado como resultado "un menguante respeto para la autoridad y una menor legitimidad institucional". El estudio concluye que este problema plantea desafíos, tanto para la seguridad como para el desarrollo y la consolidación democráticas, que son más agudos para los países con un nivel menor de desarrollo o que han atravesado situaciones de conflicto y que tienen menor capacidad para exigir la rendición de cuentas (Kavanagh, citado por Krujit, 2011: 5).

El documento del Instituto Holandés considera que no existen Estados fallidos en América Latina, aunque sí áreas donde no hay un control efectivo estatal. En el caso de México, la fragilidad se puede medir por el cálculo aproximado de que el crimen 
organizado tiene presencia y/o influencia en $50 \%$ de los municipios. Asimismo, por las estimaciones que indican que, en México, alrededor de 150000 personas están directamente involucradas en el narcotráfico y unas 500000 se ganan la vida en sectores relacionados con las drogas, mientras que 23000 jóvenes operan como el brazo armado de los cárteles. La impunidad es, por otra parte, uno de los problemas principales, ya que tiene como efecto deslegitimar la seguridad nacional y sus aparatos judiciales y penitenciarios, proceso que también arrastra, como en una avalancha, a otros actores, como los partidos políticos o los movimientos sociales (Krujit, 2011:9, $23,24)$. El mismo estudio destaca que no obstante que casi la mitad del personal del Ejército está directamente involucrado en la lucha antidrogas, la militarización no produjo los resultados esperados, pues no hubo una clara reducción de los exacerbados niveles de violencia; por el contrario, los operativos en manos del Ejército y otras fuerzas federales parecen haber contribuido a intensificarlos (Krujit,

2011: 26). De ahí que dicha investigación concluya:

es la política, y no el sistema militar ni la policía, la que debe determinar el peso relativo de los programas preventivos y las acciones represivas de la lucha antidrogas. Este autor está firmemente convencido de que la participación militar y policiaca y las prioridades del sector judicial y el sistema penitenciario necesitan someterse al debate público y así formular las prioridades políticas para que las autoridades civiles puedan tomar las decisiones acertadas (Kavanagh, citado por Krujit, 2011: 58).

Siguiendo el enfoque basado en la cohesión comunitaria que ha propuesto Suhayla Bazbaz, la seguridad tiene mucho más que ver con la construcción de lazos sociales fuertes y con el restablecimiento de la confianza entre gobierno y ciudadanos, que con la utilización de tecnologías para cerrar y vigilar los espacios públicos y privados (Bazbaz, 2011). No hay arsenal más valioso con que el Estado pueda contar que la confianza de los ciudadanos y la confianza se gana en la medida en que el Estado se someta a las normas y se aparte de los abusos y del uso discrecional del poder. En suma, lo que hemos sostenido en este tercer argumento es que las políticas del Estado han operado con base en una noción muy estrecha de seguridad que ha privilegiado el uso y el abuso de la fuerza, mientras que ha dejado de lado o no ha prestado la suficiente atención a los déficit, a los enormes rezagos socioeconómicos que han ido agrandando las distancias entre los sectores sociales, lo que ha estimulado la desconfianza y profundizado conflictos que han exacerbado la violencia.

\section{CONCLUSIONES}

Lo terrible cuando se busca la verdad, es que se le encuentra. Se la encuentra y ya no se es libre ni de seguir la pendiente del medio que nos rodea ni de aceptar los lugares comunes y corrientes

Susan Sontag (2004: 38).

Como lo han hecho notar Scheper-Hughes y Bourgois, los antropólogos hemos sido reluctantes a ocuparnos de la violencia, a documentarla con nuestro trabajo. Hemos preferido mirar para otra parte y preservar nuestra cómoda posición de observadores de fenómenos que nos coloquen en una posición menos difícil. Hemos sido, también, demasiado lentos, demasiado reflexivos para ocuparnos de acontecimientos políticos que toman tal velocidad, que solemos quedarnos atrás, rebasados, desbordados. Sin embargo, subrayan estos autores, debemos reaccionar ante las verdades a medias en nombre de las cuales la violencia suele escalar y dirigirse, casi siempre y de manera abrumadora, en contra de los jóvenes de los barrios bajos (Scheper-Hughes y Bourgois, 2004: 4).

Lo que hemos intentado en este trabajo es -además de recoger y poner sobre la mesa de debate los argumentos que los especialistas en seguridad han esgrimido para explicar el escalamiento de la violencia 


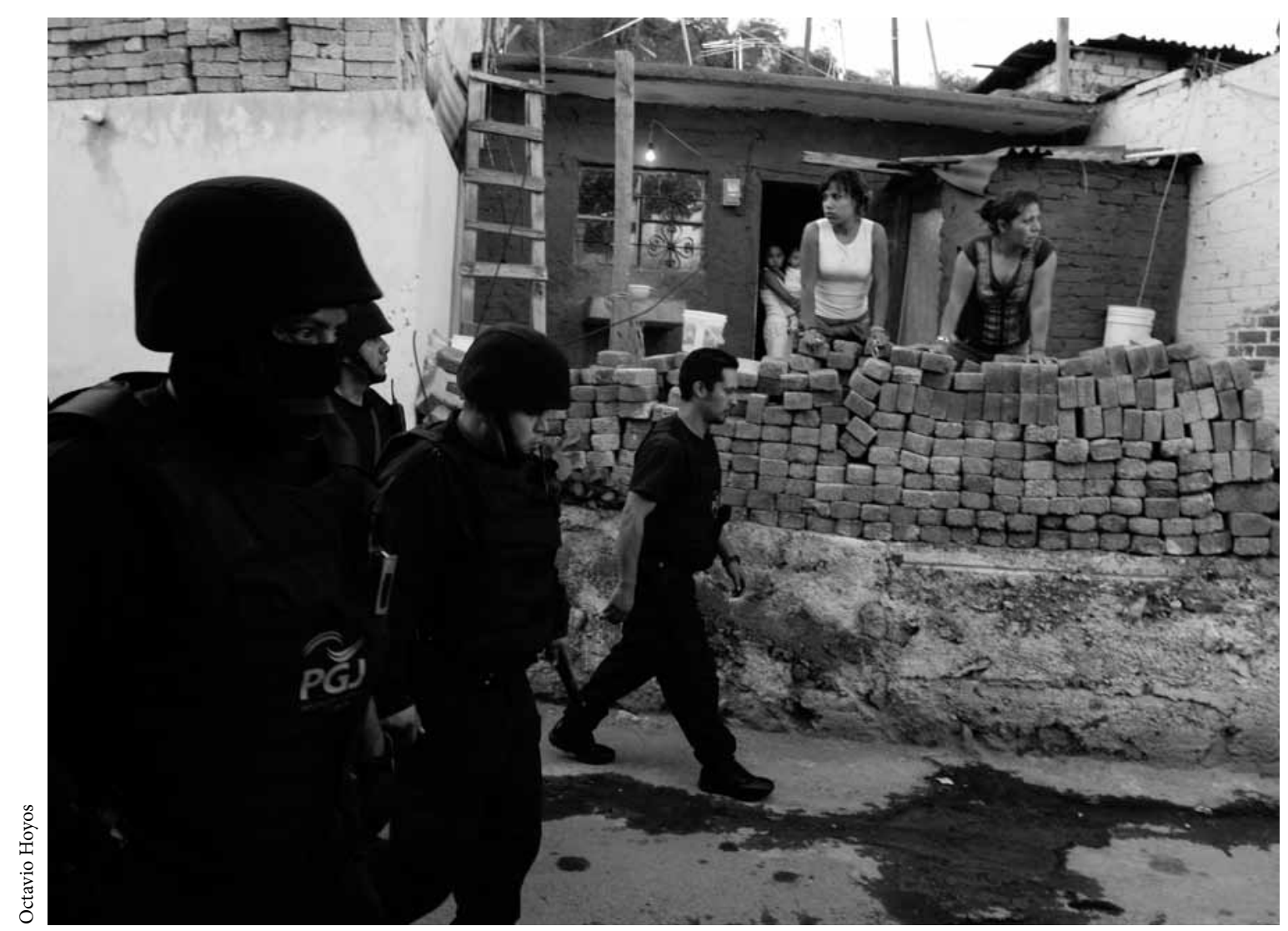

Corporaciones policiacas realizan cateos en "El Hoyo", en Iztapalapa, ciudad de México, 2008.

en nuestro país- incorporar la dimensión social sin la cual, nos parece, la seguridad no puede ser sino parcialmente comprendida. Nuestra propuesta ha sido mirar el problema de la violencia a la luz de los vínculos sociales que se tejen en las comunidades y que hacen posible la participación de contingentes cada vez más numerosos en actividades delictivas, toda vez que previamente otras formas de violencia han sido toleradas, ignoradas, pasadas por alto. Hemos mencionado el abandono por parte de instituciones del Estado de funciones sustantivas que debieron haber desempeñado para prevenir, atender y sancionar otras formas de violencia que fueron ignoradas o toleradas y que, al no recibir la respuesta que requerían en su momento, nos han condenado hoy a tener que enfrentar sus efectos acumulados. Hemos llamado la atención sobre otras deficiencias de las instituciones del Estado que, al intentar contener a la delincuencia, han incurrido en abusos que las colocan como agentes de la violencia y de la transgresión, con la consecuente pérdida de legitimidad y confianza de los ciudadanos. Hoy lidiamos con espirales de violencia difíciles de contener, cuyas repercusiones habremos de padecer durante muchos años. Lo que hemos intentado, en suma, es avanzar en el trayecto de hacer visibles los procesos sociales, económicos y políticos que están en la base y son el fundamento de los inaceptables niveles de violencia que padece nuestro país.

En resumen, en el presente trabajo hemos desarrollado tres argumentos que consideramos importantes para explicar los actuales niveles de violencia 
que tenemos en México. En el primero nos referimos a la existencia de formas de violencia que han existido de tiempo atrás, que no se relacionan directamente con las actividades de grupos de delincuencia organizada y que han sido toleradas, incluso ignoradas, y cuyos efectos acumulados, sumados a otros factores coyunturales que las han agravado, han contribuido al actual escalamiento de la violencia. Hemos denominado las formas de violencia que comprenden, entre otras, el maltrato a los niños, los abusos sexuales, los feminicidios o la violencia que tiene lugar en instituciones, las "violencias de siempre". Al exponer el segundo argumento nos referimos al debilitamiento y a la descomposición, que tampoco han recibido una respuesta apropiada, de las instituciones de seguridad y procuración de justicia, que cuentan con capacidad escasa para investigar los delitos y procesar a los responsables, lo que ha traído como consecuencia un incremento de la impunidad, que a su vez ha propiciado un crecimiento exponencial de la criminalidad en general y de la violencia en particular. Hemos agrupado estas formas de violencia -que acaparan la atención, dominan el escenario e impiden ver el sustrato del que se alimentan — bajo el nombre la "violencia de hoy". En el desarrollo de nuestro tercer argumento nos hemos referido a la insuficiencia de las políticas sociales y económicas, que no han logrado reducir las desigualdades y promover la inclusión de amplios sectores que cada día ven disminuidas sus expectativas de desarrollo. Hemos apuntado también que las políticas sociales y económicas requerirían de una mayor y mejor articulación e integración con las políticas de seguridad en torno a fines comunes. Hemos insistido en que la violencia de la desigualdad es estructural y ha sido normalizada, pero no por ello ha dejado de tener efectos que se manifiestan en los actuales niveles de violencia exacerbada que hoy se viven en nuestro país.

Haber puesto el acento en estos tres argumentos no implica que desechemos o desestimemos otros factores que también pueden haber contribuido a la escalada de violencia. Particularmente importantes son aquellos de carácter local que imponen sellos específicos a la violencia que no nos habría sido posible mencionar en este espacio con su diversidad y sus matices. Sin embargo, de manera intencional hemos querido colocarnos fuera del escenario en el que los actores que dominan son las bandas delincuenciales y las corporaciones de policía, mientras que la trama suele una y otra vez referirse a los enfrentamientos o bien a la complicidad que impide distinguir a unos de otros y que invariablemente culmina con el saldo en el número de muertos que la puesta en escena del combate ha arrojado. En este sentido, hemos preferido mirar el fenómeno haciendo intervenir a otros actores o a los mismos pero vistos desde el seno de la familia donde crecieron y en la que posiblemente fueron sujetos de malos tratos, abusos o negligencia, o desde el seno de la comunidad que, como sujeto de políticas oficiales, también cuenta en su haber con algún cúmulo de abusos, deficiencias o la falta de respuesta a sus necesidades. Me interesaba mostrar el resultado de esta última trama y hacer evidentes los vínculos que, como he intentado sostener, es posible trazar entre las "violencias de siempre" a las que nos hemos acostumbrado y la "violencia de hoy" en la que nos sentimos entrampados. Esta puesta en escena muestra a un Estado debilitado que, sin embargo, se equivoca cuando acude al uso intensivo de la fuerza para recuperar su vitalidad cuando la mejor apuesta residiría en fortalecer los vínculos y la cohesión sociales que, precisamente, se han visto desgastados tras el uso y, sobre todo, los abusos, de la fuerza.

\section{Bibliografía}

Arteaga, Nelson y Jimena Valdés Figueroa, 2010, "Contextos socioculturales de los feminicidios en México: nuevas subjetividades femeninas", en Revista Mexicana de Sociología, año 72, núm. 1, pp. 5-35.

Azaola, Elena 2001, El delito de ser mujer. Hombres y mujeres homicidas en la ciudad de México, Plaza y Valdés, Centro de Investigaciones y Estudios Superiores en Antropología Social, México. 
,2008, Crimen, castigo y violencias en México, Facultad Latinoamericana de Ciencias Sociales, Centro de Investigaciones y Estudios Superiores en Antropología Social, Ecuador, México.

- (coord.), 2009, Informe Nacional sobre Violencia de Género en la Educación Básica en México, Secretaría de Educación Pública, Fondo de las Naciones Unidas para la Infancia, México.

Banco Interamericano de Desarrollo (BID), 1999, Violence in Latin America and the Caribbean: A Framework for Action, Banco Interamericano de Desarrollo, Washington, D.C.

Banco de México (Banxico), 2012, "Durante 2012 se crearán en México entre 500 mil y 600 mil empleos formales", comunicado de prensa, 6 de enero, en línea: $<$ www.banxico.org.mx>.

Banco Mundial (BM), 1998, Determinants of Crime Rates in Latin America and the World: An Empirical Assessment, Banco Mundial, Washington, D. C.

Bazbaz, Suhayla, 2011, "El enfoque de cohesión comunitaria y el cambio de paradigma para su fortalecimiento en México", presentación, Sesión de Diálogos por la Seguridad, Campo Marte, enero.

Bobbio, Norberto, 2000, El problema de la guerra y las vías de la paz, Gedisa, Barcelona.

Briceño-León, Roberto, 2008, "La violencia homicida en América Latina”, en América Latina Hoy, vol. 50, pp. 103-116.

Canetti, Elias, 2010, Libro de los muertos, Galaxia Gutenberg, Barcelona.

Centro de Investigación para el Desarrollo, A. C. (CIDAC), 2009, Índice de incidencia delictiva y violencia, Centro de Investigación para el Desarrollo, A.C., México.

Chesnais, Jean-Claude, 1992, “The History of Violence: Homicide and Suicide through the Ages", en International Social Science Journal, núm. 44, pp. 217-245.

Coetzee, John Maxwell, 2006, Esperando a los bárbaros, Random House, España.

Comisión Económica para América Latina y el Caribe (CEPAL), 2011, Panorama Social de América Latina 2011, Comisión Económica para América Latina y el Caribe, Santiago de Chile.

Comisión Nacional para Prevenir y Erradicar la Violencia Contra las Mujeres (CNPEVM), 2010, Primeras conclusiones de los diagnósticos sobre las causas económicas, sociales y culturales de la violencia social y de género en seis ciudades mexicanas, Comisión Nacional para Prevenir y Erradicar la Violencia Contra las Mujeres, México.

Cruz, José Miguel, 2010, "Estado y violencia criminal en América Latina”, en Nueva Sociedad, núm. 226, marzo-abril, pp. 67-84.
Escalante, Fernando, 2011, "Homicidios 2008-2009. La muerte tiene permiso", en Nexos, en línea: <http://www. nexos.com.mx/?P=leerarticulo\&Article $=1943189>$.

_ et al., 2011, "Nuestra guerra: una conversación", en Nexos, en línea: <http://www.nexos.com.mx/?P=le erarticulo\&Article $=2102417>$.

Flores, Carlos, 2011, "Un asunto de impunidad: la colusión entre delincuencia organizada y la política y su efecto en la crisis de violencia en México", en prensa.

Guerrero, Eduardo, 2010, "Cómo reducir la violencia en México", en Nexos, en línea: <http://www.nexos.com. $\mathrm{mx} /$ ?P=leerarticulo\&Article $=1197808>$.

__ 2011, "La raíz de la violencia”, en Nexos, en línea: $<$ http://www.nexos.com.mx/?P=leerarticulo\&Artic le $=2099328>$.

Hirschi, Travis, 2002, “Control Theories”, en Encyclopedia of Crime and Punishment, vol. 1, Sage Publications, Thousand Oaks, pp. 311-315.

Human Rights Watch (HRw), 2011, Ni seguridad, ni derechos. Ejecuciones, desapariciones y tortura en la "guerra contra el narcotráfico", Human Rights Watch, Washington, D. C.

International Centre for Science in Drug Policy (ICSDP), 2010, Effect of Drug Law Enforcement on Drug-Related Violence: Evidence form a Scientific Review, International Centre for Science in Drug Policy, Vancouver.

Kleiman, Mark, 2011, "Surgical Strikes in Drug Wars. Smart Policies for Both Sides of the Border", en Foreign Affairs, vol. 90, núm. 5, pp. 89-101.

Krujit, Dirk, 2011, "Drogas, democracia y seguridad. El impacto del crimen organizado en el sistema político", en América Latina, Netherlands Institute for Multiparty Democracy, Países Bajos.

Kumate, Jesús, Jaime Sepúlveda y Gonzalo Gutiérrez, 1993, Información en salud: la salud en cifras, Secretaría de Salud, México.

Lozano, Rafael et al. (coords.), 2006, Informe Nacional sobre Violencia y Salud, Secretaría de Salud, Programa de Naciones Unidas para el Desarrollo, México.

México Evalúa, 2009, Indicadores para entender y monitorear la seguridad pública en México, México Evalúa, México.

_, 2011, El gasto en seguridad. Observaciones de la Auditoría Superior de la Federación a la gestión y uso de recursos, México Evalúa, México.

Organización Panamericana de la Salud (ops), 2003, Informe Mundial sobre la Violencia y la Salud, Organización Panamericana de la Salud, Washington, D. C.

Organización para la Cooperación y el Desarrollo Económicos (OCDE), 2011, Divided we Stand: Why Inequality Keeps Rising, Organización para la Cooperación y el Desarrollo Económicos, París. 
Orwell, George, 2001, “Rebelión en la granja”, en José Antonio Aguilar Rivera, La tribuna del sentimiento, en Nexos, núm. 281, en línea: <http://www.nexos.com. $\mathrm{mx} /$ ? $\mathrm{P}=$ leerarticulo\&Article $=2100032>$.

Pascual, Carlos, 2010, "México en una encrucijada", conferencia impartida por el embajador de Estados Unidos en México, El Colegio de México, 24 de noviembre.

Presidencia de la República, 2007, Plan Nacional de Desarrollo 2007-2012, "Eje 1. Estado de Derecho y Seguridad", Presidencia de la República, México.

— 2010, Cuarto Informe de Gobierno, en línea: <http://cuarto.informe.gob.mx/informe-de-gobierno/ cuarto-informe-de-gobierno $>$.

—, 2011, Quinto Informe de Gobierno, en línea: $<$ http://quinto.informe.gob.mx/informe-de-gobierno/quinto-informe-de-gobierno/>.

Procuraduría General de la República (PGR), 2011, "Fallecimientos por presunta rivalidad delincuencial, 20062011", Procuraduría General de la República, en línea: $<$ www.pgr.gob.mx $>$.

Programa de Naciones Unidas para el Desarrollo (PNUD), 2007, Informe sobre derechos humanos. México 20062007: migración y desarrollo humano, Programa de Naciones Unidas para el Desarrollo, México.

Scheper-Hughes, Nancy y Philippe Bourgois, 2004, Vioblishing, Oxford.

Secretaría de Seguridad Pública (ssP), 2007, Estrategia integral para la prevención del delito y el combate a la delincuencia, Secretaría de Seguridad Pública, en línea: $<$ http://www.oas.org/dsp/documentos/politicas_publicas/mexico_estrategia.pdf $>$.

— , 2010, "Seguridad pública en México", Secretaría de Seguridad Pública, México, inédito.

Sontag, Susan, 2004, "Perpetuo: vigencia de Víctor Serge", en Letras Libres, núm. 66.

United Nations Office on Drugs and Crime (UNODC), 2010, Homicide Statistics-Latest Available Year, United Nations Office on Drugs and Crime, en línea: <www. unodoc.org $>$.

Yonas Michael et al., 2007, "Neighborhood-level Factors and Youth Violence: Giving Voice to the Perceptions

of Prominent Neighborhood Individuals", en Health, Education and Behavior, Sage, núm. 34, pp. 669-685.

\section{Hemerografía}

“Una epidemia de tristeza”, en La Crónica de Hoy, 30 de agosto de 2009.

“¿La más violenta?”, en Reforma, 10 de enero de 2010.

"Hay 40 mil niños huérfanos por la violencia generada del crimen organizado", en Excélsior, 1 de enero de 2011.

"Acumula quejas el INM", en Reforma, 15 de enero de 2011.

"Plagian en 6 meses a 10 mil migrantes", en Reforma, 7 de enero de 2011.

“Clasifican a México como país en guerra”, en Reforma, 12 de enero de 2011.

"Juvenicidio masivo", en El Universal, 21 de septiembre de 2011.

"Desciende México 15 lugares en desarrollo humano, según el PNUD", en La Jornada, 3 de noviembre de 2011.

“Detienen a 3 mil; consignan 37\%", en Reforma, 7 de noviembre de 2011.

“Campos Elíseos”, en El Universal, 11 de noviembre de 2011.

"Alerta repunte de feminicidios", en Reforma, 23 de noviembre de 2011.

"CNDH recibe cada hora una queja por abusos de agentes federales", en La Crónica de Hoy, 28 de noviembre de 2011.

"Militares o agentes federales cometen tres cateos ilícitos diariamente: CNDH", en La Crónica de Hoy, 30 de noviembre de 2011.

"Urge reconversión productiva", en Reforma, 30 de noviembre de 2011.

"La lucha contra el abuso en el combate al crimen", en El Universal, 23 de diciembre de 2011.

"Ligan violencia con impunidad", en Reforma, 16 de enero de 2012.

“De 87,000 detenidos sólo 3\% está ligado al crimen”, en $\mathrm{La}$ Crónica de Hoy, 16 de enero de 2012. 